\title{
POST-NEONATAL INFANT MORTALITY IN BIRMINGHAM BETWEEN 1947 AND 1956
}

\author{
BY \\ GEORGE KNOX* and JEAN MACKINTOSH $\dagger$ \\ From the Department of Social Medicine, University of Birmingham
}

The three main groups of deaths in early lifestillbirths, deaths in the first month, and deaths in the second to twelfth months-have characteristic distributions with respect to birth rank and maternal age. The risk of post-neonatal death is greatest for children of higher birth ranks and this has been especially evident among the later children of young mothers (Elderton, 1928; Gibson and McKeown, 1952; Baird, Thomson, and Duncan, 1953; Heady, Daly, and Morris, 1955).

It seems likely that these effects have been produced in two main ways. First, infections were brought into the household by older children; the birth rank effect was shown to be far greater for infective than non-infective deaths (Gibson and McKeown, 1952). Second, the increased effect of high birth rank when the mother was young suggests that the risk was influenced by factors especially associated with a very early start to child-bearing and with closely-spaced pregnancies, and that analysis in terms of rank and age together reflected a wide range of social circumstances which less directly but no less potently may have influenced the chances of survival.

Since these demonstrations were presented infant mortality has fallen yet further. Much of the continuing fall seems attributable to the prevention and treatment of serious infective illness and this accounts for the disproportionate fall in post-neonatal mortality compared with stillbirths and neonatal death rates. In a time of such rapid change, it is of interest to ask what has been happening to the association between high risks and certain birth rank/maternal age groups and to the separate interactions of the latter with changes in infective and in non-infective death rates. These questions are particularly relevant at the present time because

* Medical Research Council Clinical Research Fellow. tSenior Fellow, supported by a grant from the Nuffield Provincial
Hospitals Trust. the incidence of infective deaths is now so low that we must expect a deceleration in the very rapid decline of overall mortality which has been attributed to their control, and there are in fact indications that this has already begun.

The general purpose of the present study is to examine the changes that have taken place in Birmingham in the decade 1947 to 1956 and to interpret them against this background. Its particular objects are:

(1) to enquire to what extent the association between infant mortality and birth rank and maternal age has altered since 1947;

(2) to examine the changes in post-neonatal mortality classified according to cause.

\section{MATERIAL}

This examination is based upon analyses by birth rank and maternal age of live births to residents of the City of Birmingham and the children who were known to have died in their second to twelfth months. Dates refer to the year of birth whether death occurred in that year or in the following year.

The full data for 1947 and the live-birth data for 1950 and 1953 have already been published (Gibson and McKeown, 1952; Padley and Taylor, 1952, Padley and Neale, 1954); the live-birth data for 1951, 1952, and 1954 to 1956 were supplied by the Central Statistical Office of the City of Birmingham, but data for 1948 and 1949 were not readily available and these years have been excluded. The data relating to the deaths in the years 1950-1956 were obtained by analysis of existing Maternity and Child Welfare records for these years.

The birth rank statistic used is the number of previous live births: $0 ; 1 ; 2$; and 3 or more. The mother's age at the time of birth is also used in a 
condensed form with three groups of approximately equal size: under 25 years; 25 to 29 years; and $\mathbf{3 0}$ or more years. Rates are given as deaths per related 1,000 live births.

Causes of death are based upon the death certificates and are broadly grouped as follows:

(1) Infective causes (mainly pneumonia, bronchitis, gastro-enteritis, infectious fevers, tuberculosis and meningitis; convulsions have also been classed as infective);

(2) Non-infective causes (mainly malformations, accidents and neoplasms);

(3) Indeterminate causes (for example atrophy, debility, prematurity, cirrhosis, "nephritis").

\section{RESULTS}

Tables I and II show the distribution according to birth rank and maternal age of the 128,496 infants born alive in the period 1950 to 1956 , and of the 1,030 related post-neonatal deaths.

\section{TABLE I}

NUMBERS OF LIVE BIRTHS ACCORDING TO BIRTH RANK AND MATERNAL AGE: BIRMINGHAM 1950-56

\begin{tabular}{c|c|c|c|c}
\hline \multirow{2}{*}{$\begin{array}{c}\text { Previous } \\
\text { Live } \\
\text { Births }\end{array}$} & \multicolumn{3}{|c|}{ Maternal Age (yrs) } & \multirow{2}{*}{ Total } \\
\cline { 2 - 3 } & Under 25 & $25-29$ & 30 and Over & \\
\hline 0 & 26,154 & 14,040 & 8,039 & 48,233 \\
1 & 10,099 & 13,777 & 12,475 & 36,351 \\
2 & 2,901 & 7,015 & 10,138 & 20,054 \\
3 and Over & 1,003 & 5,517 & 17,338 & 23,858 \\
\hline Total & 40,157 & 40,349 & 47,990 & 128,496 \\
\hline
\end{tabular}

TABLE II

NUMBERS OF POST-NEONATAL INFANT DEATHS OF CHILDREN BORN IN 1950-56 ACCORDING TO BIRTH RANK AND MATERNAL AGE

\begin{tabular}{c|r|c|c|c}
\hline $\begin{array}{c}\text { Previous } \\
\text { Live } \\
\text { Births }\end{array}$ & \multicolumn{3}{|c|}{ Maternal Age (yrs) } & Total \\
\cline { 2 - 4 } & Under 25 & $25-29$ & 30 and Over & \\
\hline 0 & 165 & 61 & 38 & 264 \\
1 & 114 & 82 & 78 & 274 \\
2 & 44 & 81 & 55 & 180 \\
3 and Over & 28 & 100 & 184 & 312 \\
\hline Total & 351 & .324 & 355 & 1,030 \\
\hline
\end{tabular}

Table III gives the distribution of death rates derived from the first two tables, and it is at once evident that the birth rank/maternal age pattern demonstrated in 1947 (Gibson and McKeown, 1952) was still present in 1950-56.

The main features of this pattern are a moderate reduction in mortality with increasing maternal age, a more marked increase in mortality with increasing birth rank, and a very distinct interaction between
TABLE III

POST-NEONATAL DEATH RATES (PER 1,000 LIVE BIRTHS) ACCORDING TO BIRTH RANK AND MATERNAL AGE: BIRMINGHAM 1950-56

\begin{tabular}{c|c|c|c|c}
\hline $\begin{array}{c}\text { Previous } \\
\text { Live } \\
\text { Births }\end{array}$ & \multicolumn{2}{|c|}{ Maternal Age (yrs) } & \multirow{2}{*}{ Total } \\
\cline { 2 - 3 } & Under 25 & $25-29$ & 30 and Over & \\
\hline 0 & $6 \cdot 3$ & $4 \cdot 3$ & $4 \cdot 7$ & $5 \cdot 5$ \\
1 & $11 \cdot 3$ & 6.0 & $6 \cdot 3$ & $7 \cdot 5$ \\
2 & $15 \cdot 2$ & $11 \cdot 5$ & 5.4 & $9 \cdot 0$ \\
3 and Over & 27.9 & $18 \cdot 1$ & $10 \cdot 6$ & $13 \cdot 1$ \\
\hline Total & $8 \cdot 7$ & 8.0 & $7 \cdot 4$ & $8 \cdot 0$ \\
\hline
\end{tabular}

The stepped lines divide this Table into three parts: the upper right portion with a relatively low mortality rate will henceforth be referred to as Zone $I$, the lower left part with a high mortality rate as Zone III, and the intermediate region as Zone II.

the two factors producing the pattern expressed in Fig. 1 (opposite).

It may be represented as a low incidence zone (Zone 1) including the first babies of mothers under 25 years, the first and second babies of mothers aged 25 to 29 and the first, second and third babies of mothers aged 30 or over, together with zones of greater risk (Zones II and III) at successive higher ranks. The highest rate for a single birth rank/ maternal age group is about six times the lowest, and even the three broad zones indicated in Table III exhibit successively a doubling and trebling of the lowest rate. Viewed in terms of age-cohorts, this represents high mortalities among the subsequent babies of mothers who first became pregnant at early age and/or those whose successive pregnancies closely followed each other.

Table IV gives an analysis of the secular trend of the post-neonatal mortality rate according to maternal

\section{TABLE IV}

POST-NEONATAL INFANT MORTALITY RATES (PER 1,000 LIVE BIRTHS) AT DIFFERENT BIRTH RANKS AND AT DIFFERENT MATERNAL AGES ACCORDING TO YEAR OF BIRTH

\begin{tabular}{|c|c|c|c|c|c|c|c|c|}
\hline \multirow{2}{*}{$\begin{array}{c}\text { Year } \\
\text { of } \\
\text { Birth }\end{array}$} & \multicolumn{3}{|c|}{ Maternal Age (yrs) } & \multirow{2}{*}{$\begin{array}{c}\text { Total } \\
\text { Mortal- } \\
\text { ity }\end{array}$} & \multicolumn{4}{|c|}{ Previous Live Births } \\
\hline & $\underset{25}{\text { Under }}$ & $25-29$ & $\begin{array}{l}30 \text { and } \\
\text { Over }\end{array}$ & & $\mathbf{0}$ & 1 & 2 & $\begin{array}{l}3 \text { and } \\
\text { Over }\end{array}$ \\
\hline 1947 & $20 \cdot 4$ & $17 \cdot 6$ & $15 \cdot 3$ & $17 \cdot 6$ & $11 \cdot 5$ & $17 \cdot 4$ & $22 \cdot 7$ & $27 \cdot 9$ \\
\hline 1950 & $9 \cdot 4$ & $9 \cdot 2$ & $10 \cdot 3$ & $9 \cdot 7$ & 6.6 & 7.4 & $10 \cdot 6$ & 19.4 \\
\hline 1951 & $9 \cdot 1$ & $11 \cdot 5$ & $8 \cdot 3$ & $9 \cdot 6$ & $6 \cdot 2$ & $8 \cdot 1$ & $8 \cdot 5$ & $19 \cdot 7$ \\
\hline 1952 & $9 \cdot 1$ & 6.5 & $8 \cdot 3$ & $8 \cdot 0$ & $5 \cdot 8$ & $6 \cdot 5$ & $11 \cdot 2$ & $12 \cdot 0$ \\
\hline 1953 & $8 \cdot 8$ & $8 \cdot 2$ & $5 \cdot 2$ & $7 \cdot 3$ & $4 \cdot 5$ & $8 \cdot 1$ & $9 \cdot 4$ & $10 \cdot 0$ \\
\hline 1954 & $8 \cdot 3$ & $5 \cdot 4$ & $6 \cdot 7$ & $6 \cdot 8$ & $5 \cdot 5$ & $5 \cdot 8$ & $8 \cdot 5$ & $9 \cdot 4$ \\
\hline 1955 & $8 \cdot 2$ & $5 \cdot 9$ & $6 \cdot 1$ & $7 \cdot 3$ & $4 \cdot 1$ & $9 \cdot 1$ & $6 \cdot 4$ & $11 \cdot 0$ \\
\hline 1956 & $8 \cdot 3$ & $6 \cdot 9$ & $7 \cdot 0$ & $7 \cdot 4$ & $5 \cdot 6$ & $7 \cdot 7$ & $8 \cdot 2$ & $9 \cdot 9$ \\
\hline
\end{tabular}




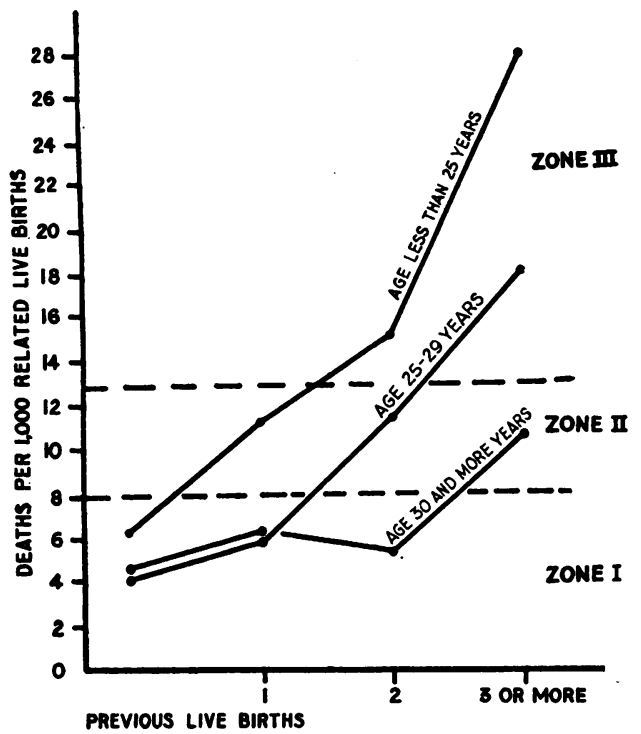

Fig. 1.-Post-neonatal mortality rates by birth rank at different maternal ages, Birmingham, 1950-56

age and according to birth rank. The total rates for each year (centre column of Table IV) show a tendency for the declining rate to level off. It is also evident from Table IV, as well as from the first panel of Table $\mathrm{V}$, that the fall in mortality over ten years has affected all groups of children but that it has been proportionately greater in the groups where it was and still is the highest (see Fig. 2). Since 1950, indeed, mortality from all causes in Zone I has been virtually static. The total picture then is of a heterogeneous population, one part of which has already reaped most of the rewards of the current phase of declining mortality and the other part of which, still with some distance to go, nevertheless is catching up and causing some narrowing of differentials.

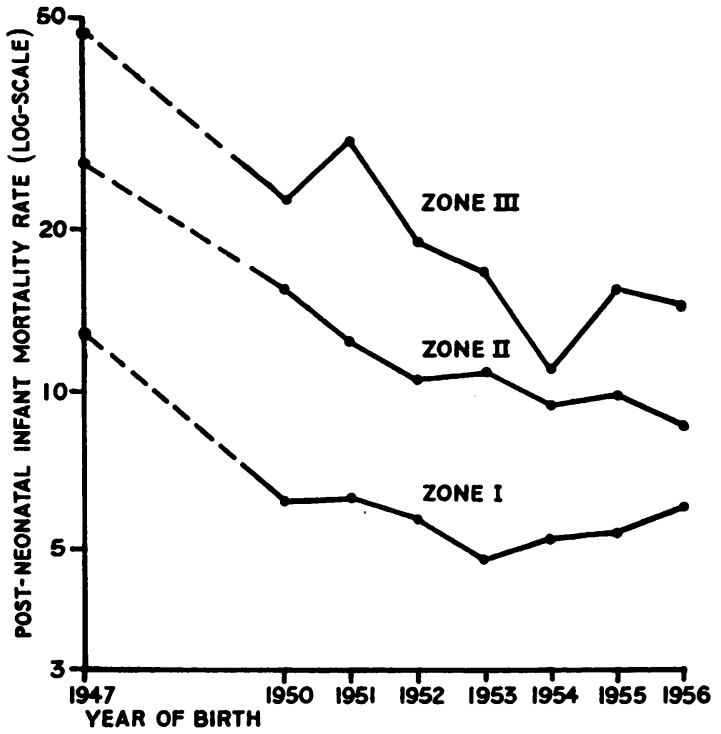

FIG. 2.-Post-neonatal mortality trends in different Birth Rank/ Maternal Age zones.

Table $\mathrm{V}$ also gives an analysis of infective and non-infective mortality rates between 1947 and 1956 and confirms that their relative proportions have changed. Infective deaths showed a steady if decelerating fall while non-infective deaths did not change much over the ten years, falling a little at first and rising again later. The centre panels of Table V supply the detail that the infective mortality fell somewhat faster in Zones II and III than in Zone I and resulted towards the end of the period in some narrowing of the difference between them (see also Fig. 3, overleaf).

It is also clear that the zonal differential is as consistent from year to year in the non-infective mortality as it is for the infective deaths and proportionately is not much less. This perhaps is an

TABLE V

POST-NEONATAL INFANT MORTALITY RATES ACCORDING TO CAUSE IN DIFFERENT BIRTH RANK/MATERNAL AGE ZONES

\begin{tabular}{|c|c|c|c|c|c|c|c|c|c|}
\hline \multirow{2}{*}{$\begin{array}{c}\text { Year of } \\
\text { Birth }\end{array}$} & \multirow{2}{*}{$\begin{array}{l}\text { Zone I } \\
\text { Total }\end{array}$} & \multirow{2}{*}{$\underset{\text { Total }}{\text { Zone II }}$} & \multirow{2}{*}{$\begin{array}{c}\text { Zone III } \\
\text { Total }\end{array}$} & \multicolumn{2}{|c|}{ Zone I } & \multicolumn{2}{|c|}{ Zones II and III } & \multicolumn{2}{|c|}{ All Births } \\
\hline & & & & Infective & Non-Infective & Infective & Non-Infective & Infective & Non-Infective \\
\hline 1947 & $12 \cdot 1$ & $25 \cdot 7$ & $47 \cdot 4$ & $9 \cdot 0$ & $3 \cdot 1$ & $25 \cdot 5$ & $4 \cdot 3$ & $14 \cdot 2$ & $3 \cdot 4$ \\
\hline $\begin{array}{l}1950 \\
1951 \\
1952 \\
1953 \\
1954 \\
1955 \\
1956\end{array}$ & $\begin{array}{l}6 \cdot 2 \\
6 \cdot 3 \\
5 \cdot 7 \\
4 \cdot 8 \\
5 \cdot 3 \\
5 \cdot 4 \\
6 \cdot 0\end{array}$ & $\begin{array}{r}15.4 \\
12.3 \\
10.5 \\
11.0 \\
9.4 \\
9.8 \\
8.6\end{array}$ & $\begin{array}{l}22.6 \\
29.4 \\
19.0 \\
16.7 \\
11.0 \\
15.6 \\
14.4\end{array}$ & $\begin{array}{l}4 \cdot 0 \\
3 \cdot 4 \\
3 \cdot 5 \\
3 \cdot 3 \\
2 \cdot 6 \\
2 \cdot 7 \\
2 \cdot 5\end{array}$ & $\begin{array}{l}1 \cdot 5 \\
1 \cdot 7 \\
1 \cdot 9 \\
1 \cdot 0 \\
2 \cdot 0 \\
2 \cdot 0 \\
2 \cdot 9\end{array}$ & $\begin{array}{r}12 \cdot 3 \\
10 \cdot 2 \\
7 \cdot 7 \\
7 \cdot 6 \\
5 \cdot 3 \\
5 \cdot 3 \\
5 \cdot 0\end{array}$ & $\begin{array}{l}3 \cdot 7 \\
4 \cdot 6 \\
3 \cdot 1 \\
4 \cdot 0 \\
2 \cdot 7 \\
5 \cdot 1 \\
3 \cdot 6\end{array}$ & $\begin{array}{l}6 \cdot 7 \\
5 \cdot 7 \\
4 \cdot 9 \\
4 \cdot 7 \\
3 \cdot 5 \\
3 \cdot 6 \\
3 \cdot 4\end{array}$ & $\begin{array}{l}2 \cdot 2 \\
2 \cdot 7 \\
2 \cdot 3 \\
2 \cdot 3 \\
2 \cdot 0 \\
3 \cdot 3 \\
3 \cdot 1\end{array}$ \\
\hline
\end{tabular}

Discrepancies between totals and the sum of infective and non-infective rates are due to omission from this table of deaths from indeterminate causes. These amount ot one-tenth of all the deaths (103 of the 1030). 


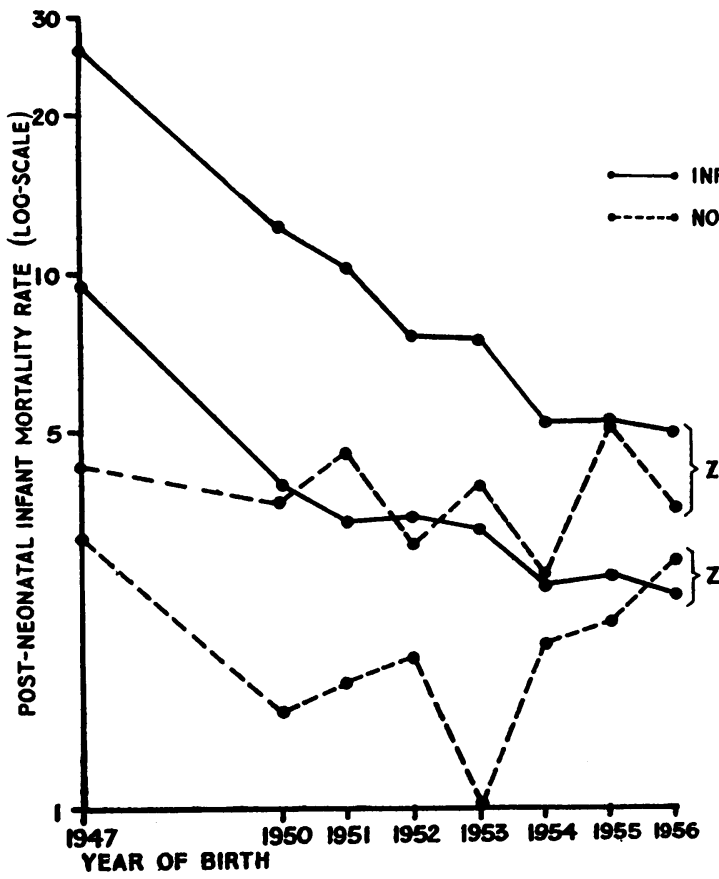

FIG. 3.-Post-neonatal mortality according to cause in different Birth Rank/Maternal Age zones.

indication of the importance of indirect social factors in the determination of the birth rank/maternal age differences in overall mortality.

Yet, despite the importance of such factors in determining the death rates both from infective and non-infective illness, one group has declined in frequency and the other has not. Moreover, the reduction of social differentials over the ten years, though present, was not impressive. We must conclude that the main improvements of the last decade were due to causes not correlated with the social differences expressed in the birth rank/maternal age analysis and that the wide use of antibiotics and other modern treatments probably played a much greater part than any narrowing of these differences. This all lends force to the view that the recent rapid improvements are now coming to an end and that future advances will depend increasingly upon improved fundamental understanding of non-infective diseases, and the means of preventing and treating them, and upon attention to those social factors which still maintain the mortality differences between different groups.

\section{SUMMARY}

The birth rank/maternal age distribution of post-neonatal infant mortality rates in Birmingham in 1947 is shown to have persisted over the following ten years despite a large overall reduction and a small degree of narrowing of the differentials. Although these differentials were as consistent for non-infective as for infective deaths the reduction of mortality over these ten years has been due entirely to a reduction in the latter group. It is concluded that the recent period of rapidly declining mortality was due mainly to therapeutic advances in the field of infective disease and that this period is now ending.

The authors gratefully acknowledge their indebtedness to Dr. Enid Charles who designed the original records, to Dr. Richard Padley who succeeded Dr. Charles as Chief Statistical Officer, Birmingham, during the period 1953-1957, and to Mr. A. B. Neale, Corporation Statistical Officer. We should also like to express our thanks to Dr. Matthew Burn and the members of his staff for their cooperation.

\section{REFERENCES}

Baird, D., Thomson, A. M., and Duncan, E. H. L. (1953). J. Obstet. Gynaec. Brit. Emp., 60, 17.

Elderton, E. M. (1928). "On the Relative Value of the Factors which Influence Infant Welfare". Eugenics Laboratory Memoirs XXV. Cambridge University Press, London.

Gibson, J. R., and McKeown, T. (1952). Brit. J. soc. Med., 6, 183.

Heady, J. A., Daly, C., and Morris, J. N. (1955). Lancet, 1, 395.

Padley, R., and Taylor, W. (1952). "City of Birmingham Annual Abstract of Statistics. 1950-1951". Central Statistical Office, Birmingham.

- and Neale, A. B. (1954). "City of Birmingham Annual Abstract of Statistics. 1952-1953”. Central Statistical Office, Birmingham. 